\title{
Linearization of the Navier-Stokes equations
}

\author{
Serdar Nazarov ${ }^{1}$, Muhammetberdi Rakhimov ${ }^{1, *}$, and Gurbanyaz Khekimov ${ }^{1}$ \\ ${ }^{1}$ State Energy institute of Turkmenistan, city Mary, Mary region, Turkmenistan
}

\begin{abstract}
This paper studies mathematical models of the heat transfer process of a viscous incompressible fluid. Optimal control methods are used to solve the problem of optimal modeling. Questions of linearization of the Navier-Stokes equation for a plane fluid flow are considered. The optimal modes (optimal functional dependencies) of the pump and heating device are found depending on the fluid flow rate.
\end{abstract}

\section{Introduction}

In [1], the problems of modeling the process of heat transfer of a viscous incompressible fluid and linearization of the Navier-Stokes equations were considered, and it was proposed to use the solution of the problem of optimal control of the heat transfer process to linearize the non-stationary nonlinear Navier-Stokes equations. In this paper, we demonstrate the method of linearization of nonstationary nonlinear Navier-Stokes equations indicated in [1] using the example of the first boundary value problem for a plane fluid flow. In this case, to facilitate the calculation of linearization, the selected (maybe averaged) values of the components of the fluid velocity vector are used. It is indicated that to obtain a closed solution for the optimal simulation of the heat transfer process of a viscous incompressible fluid, it is convenient to use the Fourier method to solve the initial-boundary value problem.

In the literature [2-5] on the study of mathematical models of the heat transfer process, basically, two problems are noted: 1) physical issues of the adequacy of mathematical models of the heat transfer process; 2) mathematical questions of research of nonlinear NavierStokes equations. There is an extensive literature list on solutions to these problems. It is impossible to list them. A review of works devoted to these problems is beyond the scope of this article. Let us note some of them, which deal with mathematical questions of problems. In [5], a fairly wide list of references on numerical methods for solving Navier-Stokes is given. A complete reduced mathematical model of the hydrodynamic process, depending on the physical parameters, is indicated. For the numerical solution of the initial-boundary value problem for the Navier-Stokes equations, the Galerkin method is applied. In [6], the questions of the influence of variability of thermophysical parameters (heat capacity, thermal conductivity, and viscosity) of air on the result of the accuracy of the numerical solution and averaging of the Navier-Stokes equations are considered. It is shown that this influence leads to the appearance of modeled terms in the averaged and filtered NavierStokes equations. There are numerous scientific works devoted to numerical methods for solving boundary value problems for the Navier-Stokes equations in various settings, see, for example, [2-7].

\section{Statement of the optimization problem for two-dimensional vector differential Navier-Stokes equations.}

For a nonstationary and nonlinear two-dimensional (the three-dimensional case is considered similarly) vector differential Navier-Stokes equation, consider the initialboundary conditions (the density is assumed to be $\rho=1$ ) [1-5]:

$$
\begin{aligned}
& \left\{\begin{array}{c}
\frac{\partial v_{1}}{\partial t}+\alpha\left(v_{1} \frac{\partial v_{1}}{\partial x}+v_{2} \frac{\partial v_{1}}{\partial y}\right)= \\
=-\frac{\partial p}{\partial x}+v \Delta v_{1}+f_{1}+q_{1} \\
\frac{\partial v_{2}}{\partial t}+\alpha\left(v_{1} \frac{\partial v_{2}}{\partial x}+v_{2} \frac{\partial v_{2}}{\partial y}\right)= \\
-\frac{\partial p}{\partial y}+v \Delta v_{2}+f_{2}+q_{2} \\
\frac{\partial v_{1}}{\partial x}+\frac{\partial v_{2}}{\partial y}=0
\end{array}\right. \\
& \left\{\begin{array}{c}
v_{1}(x, y, 0)=a(x, y), v_{2}(x, y, 0)=b(x, y) ; \\
\frac{\partial a}{\partial x}+\frac{\partial b}{\partial y}=0 ; \\
v_{i}(0, y, t)=g_{i 1}(t), i=1,2, \\
v_{i}(h, y, t)=g_{i 2}(t), 0 \leq y \leq l \\
v_{i}(x, 0, t)=0, v_{i}(x, l, t)=0,0 \leq x \leq h ;
\end{array}\right.
\end{aligned}
$$

where $\alpha$ is a non-negative number; $t \in[0, T] ;(x, y) \in$ $\Omega=\{0 \leq x \leq h, 0 \leq y \leq l\}$-rectangular region with border $-S=\{x=0, x=h ; 0 \leq y \leq l ; 0 \leq x \leq h ; y=$ $0, y=l\}, Q_{T}=\Omega X(0, T), S_{T}=S X[0, T] ; \Delta-\Delta$ - Laplace operator $v$ constant coefficient of viscosity; $w(x, y, t)=\left(v_{1}, v_{2}\right), v_{i} \equiv v_{i}(x, y, t)-$ is the vector function of the fluid velocity, $p=p(x, y, t)$; $f=\left(f_{1}, f_{2}\right), f_{i}=f_{i}(x, y, t) ; q=\left(q_{1}, q_{2}\right)$,

*Corresponding author: e-mail: marytdei@mail.ru 
$q_{i}=q_{i}(x, y, t), i=1,2$.

It is believed that in equation (1) $p=p(x, y, t)$, $\left(\frac{\partial p}{\partial x}=p_{1}, \frac{\partial p}{\partial y}=p_{2}\right)$ 2) is the pressure, external forces $f=f(x, y, t), q=q(x, y, t)$ and under conditions (2) the functions $g_{i j}(t), a(x, y), b(x, y)$ possess the necessary differential properties. In equation (1) $\mathrm{q}$ is a constantly acting force. In the following reasoning for optimal modeling, boundary conditions of other types, for example, nonself-adjoint boundary conditions of the Bitsadze-Samarskii type, are considered similarly, with the difference that to apply the method of spectral decomposition of the solution of a boundary value problem, it is necessary to use the apparatus of the theory of nonself-adjoint operators [8]. The existence and uniqueness of a solution to problem (1), (2) were proved in [2-4]

In boundary conditions (2), the vector of the function $g_{i 2}(t)$ describes the actions of the pump in the boundary mode, and the vector function $f$ characterizes the difference between the surface temperature of the heating device and the temperature of the liquid (lifting force).

Let us formulate the problem of optimal modeling of the heat transfer process as follows.

Let $\alpha=0$, then we obtain the linear nonstationary Navier-Stokes equations [2-4] for the components of the vector function $w(x, y, t)=\left(v_{1}(x, y, t), v_{2}(x, y, t)\right)$ $\left(j_{i}=-p_{i}+q_{i}, i=1,2\right)$ :

$$
\left\{\begin{array}{c}
\frac{\partial v_{1}}{\partial t}-v \Delta v_{1}=f_{1}+j_{1} \\
\frac{\partial v_{2}}{\partial t}-v \Delta v_{2}=f_{2}+j_{2} \\
\frac{\partial v_{1}}{\partial x}+\frac{\partial v_{2}}{\partial y}=0
\end{array} .\right.
$$

Under conditions $\left(1^{\prime}\right),(2)$, the problem of optimal modeling of the heat transfer process is formulated as follows: find the control functions $g_{i j}(t), f_{i}(x, y, t)$, $i, j=1,2$, as functions of the fluid velocity, i.e. .e. find the synthesizing $f_{i}=f_{i}\left(v_{i}, t\right), g_{i j}=g_{i j}\left(v_{i}, t\right)$ control functions that depend on the components of the velocity vector $w$ and ensure that the velocity of the controlled fluid flow approaches at points $x$ and time $t$ to a given $\varphi(x, y, t)=\left(\varphi_{1}(x, y, t), \varphi_{2}(x, y, t)\right)$ the normal fluid velocity, and at the end of the controlled process also approached the specified normal velocity $\psi(x, y)=$ $\left(\psi_{1}(x, y), \psi_{2}(x, y)\right)$ and in such a way that the energies of forces (pump, heating device) acting on convective heat transfer are minimal.Then, for each component of the fluid velocity vector, the criterion of the optimal modeling problem is written as follows $[8](i=1,2)$ :

$$
\begin{aligned}
& I_{i}\left[t_{0}, g_{i}, f_{i}\right]=\alpha_{1} \int_{t_{0}}^{T} \int_{0}^{h} \int_{0}^{l}\left(v_{i}-\varphi_{i}\right)^{2} d t d x d y+ \\
& \alpha_{2} \int_{0}^{h} \int_{0}^{l}\left(v_{i}(x, y, T)-\psi_{i}(x, y)\right)^{2} d x d y+ \\
& \alpha_{3} \int_{t_{0}}^{T} \int_{0}^{h} \int_{0}^{l} f_{i}^{2}(x, y, t) d t d x d y+\int_{t_{0}}^{T}\left[\alpha_{4} g_{i 1}^{2}(t)+\right. \\
& \left.\alpha_{5} g_{i 2}^{2}(t)\right] d t,
\end{aligned}
$$

$t_{0}=0 ; \alpha_{i}(i=1,2,3,4,5)-$ given positive numbers. The end $\mathrm{T}$ of the controlled process is fixed. Thus, the optimal control problem is formulated as follows: find the synthesizing functions $f_{i}=f_{i}\left(v_{i}, t\right), g_{i}=g_{i}\left(v_{i}, t\right)$ of the control, which depend on the component $v_{i}$ of the velocity $w=\left(v_{1}, v_{2}\right)$ of the flow and together with the corresponding solution of the initial-boundary value problem 1', (2), providing the functional (3) with a minimum value.

\section{Solving the problem of optimal modeling}

By definition, we put $S\left[t_{0}, v_{i}(t,).\right]=\min _{g_{i}, f_{i}} I_{i}\left[t_{0}, g_{i}, f_{i}\right]$. In accordance with the dynamic programming method, we obtain the nonlinear functional equation of $\mathrm{R}$. Bellman $[1,8]$ :

$$
\begin{gathered}
-\frac{\partial S}{\partial t}=\min _{g_{i}, f_{i}}\left\{\alpha_{1} \int_{0}^{h} \int_{0}^{l}\left(v_{i}-\varphi_{i}\right)^{2} d \Omega+\right. \\
+\alpha_{3} \int_{0}^{h} \int_{0}^{l} f_{i}^{2}(\theta, t) d \Omega+ \\
+\int_{0}^{h} \int_{0}^{l}\left[v v_{i} \Delta u_{i}+\left(f_{i}+j_{i}\right) u_{i}\right] d \Omega+ \\
+\alpha_{4} g_{i 1}^{2}(t)+\alpha_{5} g_{i 2}^{2}(t)- \\
\left.-\int_{0}^{l}\left[v g_{i 2}(t) u_{i_{x}}(h, y, t)--v g_{i 1}(t) u_{i_{x}}(0, y, t)\right] d y\right\} \\
\left\{\begin{array}{c}
S\left[T, v_{i}(T, x)\right]==\alpha \int_{0}^{h} \int_{0}^{l}\left(v_{i}(\theta, T)-\psi_{i}(\theta)\right)^{2} d \Omega \\
\left.u_{i}\right|_{S_{T}}=0, \quad \theta=x, y,
\end{array}\right.
\end{gathered}
$$

where $u_{i}=u_{i}\left(t, v_{i}\right)-$ is the Frechet functional derivative of the Bellman functional $S\left[t, v_{i}\right]$. From equation (4) we find the control functions:

$$
\left\{\begin{array}{c}
f_{i}(x, t)=-\frac{1}{2 \alpha_{3}} u_{i}\left(t, v_{i}\right) \\
g_{i 1}(t)=-\frac{v}{2 \alpha_{4}} \int_{0}^{l} u_{i_{x}}(0, y, t) d y \\
g_{i 2}(t)=\frac{v}{2 \alpha_{5}} \int_{0}^{l} u_{i_{x}}(l, y, t) d y
\end{array}\right.
$$

The control functions found by formulas (6) are synthesizing control functions, that is, as required in the optimal modeling problem formulated above, they are functions that depend on the fluid flow rate. Substituting them into (1), (2), we obtain equations with initialboundary conditions that describe the rate of the optimal fluid flow.

\section{Solution of the Bellman equation}

We seek the Bellman functional in the form [8]

$$
\begin{gathered}
(\omega=x, y, \beta, \gamma ; \quad d \omega=d x d y d \beta d \gamma) \\
S\left[t, v_{i}(t, .)\right]=\int_{\Omega} \int_{\Omega} R(\omega, t) v_{i}(x, \beta, t) v_{i}(\gamma, y, t) d \omega+ \\
\int_{\Omega} k(x, y, t) v_{i}(x, y, t) d \Omega+\eta(t),
\end{gathered}
$$


where $R(\omega, t), k(x, y, t), \eta(t) \quad$ are continuously differentiable functions, moreover, $\mathrm{R}$ is a symmetric function in its phase coordinates, for example: $(x, y, \beta, \gamma, t) \equiv R(y, x, \beta, \gamma, t)=\cdots$.

Calculating derivatives of the functional $\mathrm{S}$ with the Frechet and $\mathrm{t}$, we find:

$$
\begin{gathered}
\frac{\partial S}{\partial t}=\int_{\Omega} \int_{\Omega} R^{\prime}(\omega, t) v_{i}(x, \beta, t) v_{i}(\gamma, y, t) d \omega+ \\
\int_{\Omega} k^{\prime}(x, y, t) v_{i}(x, y, t) d \Omega+\eta^{\prime}(t) \\
u_{i}\left(t, v_{i}\right)=2 \int_{0}^{h} \int_{0}^{l} R(\omega, t) v_{i}(\beta, \gamma, t) d \beta d \gamma+ \\
+k(x, y, t) .
\end{gathered}
$$

Hence,

$$
\begin{gathered}
\Delta u_{i}=2 \int_{0}^{h} \int_{0}^{l} \Delta R(\omega, t) \cdot v_{i}(\beta, \gamma, t) d \beta d \gamma+ \\
+\Delta k(x, y, t) .
\end{gathered}
$$

To determine the function $R(\omega, t), k(x, y, t)$ and $\eta(t)$ we obtain the following system of equations:

$$
\begin{gathered}
R^{\prime}(\omega, t)+2 v \Delta R(\omega, t)- \\
-\frac{1}{\alpha_{3}} \int_{0}^{h} \int_{0}^{l} R(x, \xi, \mu, y, t) R(\mu, \gamma, \beta, \xi, t) d \mu d \xi- \\
-\frac{v^{2}}{\alpha_{4}} \int_{0}^{l} \int_{0}^{l} R_{x}(0, \xi, x, y, t) R_{x}(0, \mu, \beta, \gamma, t) d \mu d \xi+
\end{gathered}
$$

$$
\begin{aligned}
& +\frac{v^{2}}{\alpha_{5}} \int_{0}^{l} \int_{0}^{l} R_{x}(l, \xi, x, y, t) R_{x}(l, \mu, \beta, \gamma, t) d \mu d \xi \\
& +\alpha_{1} \delta(\beta-x) \delta(\gamma-y)=0, \\
& k^{\prime}(x, y, t)+v \Delta k(x, y, t)- \\
& -\frac{1}{\alpha_{3}} \int_{0}^{h} \int_{0}^{l} R(x, y, \beta, \gamma, t) k(\beta, \gamma, t) d \beta d \gamma- \\
& -\frac{v^{2}}{\alpha_{4}} \int_{0}^{l} R_{x}(0, \xi, x, y, t) k_{x}(0, \xi, t) d \xi \\
& -\frac{v^{2}}{\alpha_{5}} \int_{0}^{l} R_{x}(l, \xi, x, y, t) k_{x}(l, \xi, t) d \xi- \\
& -2 \alpha_{1} \varphi_{i}+2 R j_{i}=0 \\
& \eta^{\prime}(t)-\frac{1}{4 \alpha_{3}} \int_{0}^{h} \int_{0}^{l} k^{2}(x, y, t) d x d y- \\
& -\frac{v^{2}}{4 \alpha_{4}} \int_{0}^{l} k^{2}(0, y, t) d y-\frac{v^{2}}{4 \alpha_{5}} \int_{0}^{l} k^{2}(l, y, t) d y+ \\
& +\int_{0}^{h} \int_{0}^{l} j_{i}(x, y, t) k(x, y, t) d x d y+ \\
& +\alpha_{1} \int_{0}^{h} \int_{0}^{l} \varphi_{i}^{2}(x, y, t) d x d y=0
\end{aligned}
$$

with initial-boundary conditions:

$$
\left\{\begin{array}{c}
R(x, y, \beta, \gamma, T)=\alpha_{2} \delta(\beta-x) \delta(\gamma-y), \\
k(x, y, T)=-2 \alpha_{2} \psi(x, y), \quad \eta(T) \\
R_{S_{T}}(x, y, \beta, \gamma t)=k_{S_{T}}(x, y, t)=0 \\
=\int_{0}^{h} \int_{0}^{l} \psi_{i}^{2}(x, y) d x d y ; \quad
\end{array}\right.
$$

where $\delta$ is the Dirac delta function.

The work [8] is devoted to the solvability of the method of spectral expansion similar to system (8) (11). Issues of spectral expansion in eigenfunctions of nonself-adjoint operators $[8,9]$ are studied, and the proposed methods of dynamic programming and spectral expansion [8] are substantiated.

\section{The solution of the Riccati equation}

To solve equation (8), it is convenient to use its operator representation from [1] with respect to the integral operator R and put $R(t)=\sum_{k l=1}^{\infty} \beta_{k l} \varphi_{k} \otimes \varphi_{l}$, where $\varphi_{k} \otimes \varphi_{l}$ is a positive operator acting from $L_{2}(\Omega)$ in $D(\Delta)$ according to the rule; $\left[\varphi_{k} \otimes \varphi_{l}\right] x=$ $\left(x, \varphi_{k}\right) \varphi_{l}, \quad \forall x \in L_{2}(\Omega) ; \quad \varphi_{l} \quad$ is orthonormal proper element of the operator $\Delta$. Then, with respect to $R=$ $R(t)=\left\|\beta_{m n}(t)\right\|$ matrix, we obtain a nonlinear matrix Riccati equation with the initial condition:

$$
\begin{aligned}
& R^{\prime}-R A-2 d R-v^{2} R M_{0} R-v^{2} R M_{1} R- \\
& -\frac{1}{\alpha_{3}} R^{2}+\alpha_{1} I=0, \\
& R(T)=\alpha_{2} I
\end{aligned}
$$

Where $\mathrm{I}$ is the identity matrix, $A$ is the diagonal matrix composed of the eigenvalues of the Laplace operator; $A=\left(\lambda_{1}^{2}, \lambda_{2}^{2}, \ldots, \lambda_{n}^{2}, \ldots\right) ; M_{0}, M_{h}$ are symmetric matrices composed of the Fourier coefficients of the boundary functions: $\quad M_{0}=\alpha_{4}^{-1}\left\|q_{0 m n}\right\|, \quad M_{1}=$ $\alpha_{5}^{-1}\left\|q_{1 m n}\right\|$. An explicit analytical solution is obtained to problem (12), (13). A detailed analysis of this solution will be provided by the authors of this article in other scientific works.

In system (8) - (11), using the found solution of the nonlinear Riccati equation (8), (12), (13) with the corresponding initial-boundary conditions (11) and substituting this solution in the linear equation (9), the linear initial -boundary value problem (9), (11). As a result, substituting the found function $k(x, y, t)$ from relations (10) and (11), we find the function $\eta(t)$. As a result, optimal controls are found from formulas (6) (11). Substituting the found optimal controls in the initial initial-boundary value problem $\left(1^{\prime}\right),(2)$, we obtain the optimal regime of the fluid velocity for the case $\alpha=0$, i.e. for a linear non-stationary heat transfer problem. In this case, it is necessary to take into account the continuity condition: $\frac{\partial v_{1}}{\partial x}+\frac{\partial v_{2}}{\partial y}=0, \frac{\partial a}{\partial x}+\frac{\partial b}{\partial y}=0$. 


\section{Linearization of the Novier - Stokes equations}

In [1], for the linearization of equation (1), we proposed to use the solution of the linear optimal modeling problem. Now we will show one of the methods of replacing a nonlinear term with a linear one in the Navier-Stokes equation by using some (maybe averaged) values of the velocity (solving the optimal linear problem) and using them as components of the fluid velocity vector in the complete Navier-Stokes equation. Let $\sigma$ and $\tau$ be the selected values of the components $v_{i}$, $i=1,2$ higher than the found optimal velocity vector in the region $Q_{T}=\Omega X(0, T)$. Then we write problem (1), (2) in the following form:

$$
\begin{gathered}
p_{1}=\frac{\partial p}{\partial x}, p_{1}=\frac{\partial p}{\partial y} \\
\left\{\begin{array}{c}
\frac{\partial v_{1}}{\partial t}+\alpha\left(\sigma \frac{\partial v_{1}}{\partial x}+\tau \frac{\partial v_{1}}{\partial y}\right)=-p_{1}+v \Delta v_{1}+f_{1}+q_{1} \\
\frac{\partial v_{2}}{\partial t}+\alpha\left(\sigma \frac{\partial v_{2}}{\partial x}+\tau \frac{\partial v_{2}}{\partial y}\right)=-p_{2}+v \Delta v_{2}+f_{2}+q_{2} \\
\frac{\partial v_{1}}{\partial x}+\frac{\partial v_{2}}{\partial y}=0
\end{array}\right. \\
\left\{\begin{array}{c}
v_{1}(x, y, 0)=a(x, y), v_{2}(x, y, 0)=b(x, y) \\
\frac{\partial a}{\partial x}+\frac{\partial b}{\partial y}=0 ; 0 \leq y \leq l ; 0 \leq x \leq h \\
v_{i}(0, y, t)=g_{i 1}(t), v_{i}(h, y, t)=g_{i 2}(t) \\
v_{i}(x, 0, t)=0, v_{i}(x, l, t)=0, i=1,2
\end{array}\right.
\end{gathered}
$$

Also, the problem of optimal modeling (3), (14), (15) can be solved for each component of the velocity vector separately.

Note that each of the first two equations (14) can be reduced to self-adjoint equations by replacing unknown functions, which is important in solving the problem by the method of separation of variables. Indeed, put: $v_{i}=$ $e^{\frac{1}{2 v}(\sigma x+\tau y)} u_{i}, i=1,2$. Then the basic equations (14) will take the form:

$$
\begin{gathered}
u_{i t}-v \Delta u_{i}+\frac{1}{4 v}\left(\sigma^{2}+\tau^{2}\right) u_{i}=F_{i}+J_{i}, \\
F_{i}=e^{-\frac{1}{2 v}(\sigma x+\tau y)} f_{i}, \quad J_{i}=e^{-\frac{1}{2 v}(\sigma x+\tau y)} j_{i} \\
j_{i}=-p_{i}+q_{i}, \quad i=1,2 .
\end{gathered}
$$

The boundary conditions for the function $u_{i}$ take the form: $0 \leq y \leq l$,

$$
\begin{array}{r}
u_{i}(0, y, t)=e^{-\frac{1}{2 v} \tau y} g_{i 1}(t) \equiv G_{i 1}(y, t), \\
u_{i}(h, y, t)=e^{-\frac{1}{2 v}(\sigma x+\tau y)} g_{i 2}(t) \equiv G_{i 2}(y, t), \\
u_{i}(x, 0, t)=u_{i}(x, l, t)=0,0 \leq x \leq h .
\end{array}
$$

The optimality criterion (3) is replaced by an equivalent functional:

$$
\begin{gathered}
I_{i}\left[t_{0}, G_{i 1}, G_{i 2}, F_{i}\right]=\alpha_{1} \int_{\mathrm{t}_{0}}^{T} \int_{0}^{h} \int_{0}^{l}\left(u_{i}-\varphi_{i}\right)^{2} d t d x d y+ \\
+\alpha_{2} \int_{0}^{h} \int_{0}^{l}\left(u_{i}(x, y, T)--\psi_{\mathrm{i}}(x, y)\right)^{2} d x d y
\end{gathered}
$$

$$
\begin{aligned}
+\alpha_{3} \int_{t_{0}}^{T} \int_{0}^{h} \int_{0}^{l} F_{1}^{2}(x, y, t) \mathrm{d} t d x d y & \\
& +\int_{t_{0}}^{T}\left[\alpha_{4} G_{i 1}^{2}(t)+\alpha_{5} G_{i 2}^{2}(t)\right] d t .
\end{aligned}
$$

Thus, as mathematical models for optimal modeling of the heat transfer process, we propose relations (16) (18). The procedure for solving optimal control problem (16) - (18) is similar. We only note that in the Bellman equation (4) and system (8), (9) new linear terms appear corresponding to the terms $\alpha\left(\sigma \frac{\partial v_{i}}{\partial x}+\tau \frac{\partial v_{i}}{\partial y}\right), i=1,2$ from equations (14). These terms will create some difficulties in solving the problem by the method of separation of variables. On the other hand, for the optimal model (14) - (16) in the corresponding equation (4) and system (8), (9), these terms will be absent. Consequently, in solving the control problem, these difficulties will be removed. In this way, the results obtained can be compared with experimental data, for which it is necessary to find the values of the first two integrals from functional (3) or (18). If necessary, this procedure of linearization of nonlinear equations (1) of the heat transfer process can be continued using the solutions of the last optimal control problem.

The proposed method is convenient in that the Fourier method can be used to obtain a closed solution of the optimal heat transfer regime, i.e. method of spectral expansion in eigenfunctions of the Laplace operator [611].

\section{Simplified equation of the Navier- Stokes equation for the boundary layer}

The new mathematical models obtained in this work make it possible to take into account the influence of external forces depending on the fluid flow rate. To apply the Navier-Stokes equations, they are usually simplified based on physical considerations. One of such simplifications can be given for a plane flow of an incompressible fluid. The differential Prandtl equations of the boundary layer follows from the Navier-Stokes equations and can be obtained as a result of a comparative assessment of the terms of these equations and the continuity equation for fluid flow at large Reynolds numbers [14]:

$$
\left\{\begin{array}{c}
v_{1} \frac{\partial v_{1}}{\partial x}+v_{2} \frac{\partial v_{1}}{\partial y}=-\frac{d p}{d x}+v \frac{\partial^{2} v_{1}}{\partial x^{2}} \\
\frac{\partial p}{\partial y}=0 \\
\frac{\partial v_{1}}{\partial x}+\frac{\partial v_{2}}{\partial y}=0
\end{array} .\right.
$$

It is noted in [14] that, at certain values of Re, the boundary layer of the laminar flow goes over to the turbulent regime, and certain corrections must be made to use the Prandtl equations. One of these possible adjustments can be made using the optimal external acting forces found above, i.e. clear functional 
dependences of the heating device and pump on the fluid flow rate. Indeed, if the above linearizations are given in system (19) and the effects of external forces are taken into account, then the following linear model of the heat transfer process can be used to calculate the parameters of the boundary layer of the fluid flow:

$$
\left\{\begin{array}{c}
\alpha\left(\sigma \frac{\partial v_{1}}{\partial x}+\tau \frac{\partial v_{1}}{\partial y}\right)=-\frac{\partial p}{\partial x}+v \frac{\partial^{2} v_{1}}{\partial y^{2}}- \\
-\frac{1}{2 \alpha_{3}} \int_{0}^{h} \int_{0}^{l} R(t, \omega) v_{1}(t, \beta, \gamma) d \alpha d \gamma- \\
-\frac{1}{2 \alpha_{3}} k_{1}(t, x, y)+q_{1} \\
\frac{\partial p}{\partial y}=-\frac{1}{2 \alpha_{3}} \int_{0}^{h} \int_{0}^{l} R(t, \omega) v_{2}(t, \beta, \gamma) d \beta d \gamma- \\
-\frac{1}{2 \alpha_{3}} k_{2}(t, x, y)+q_{2} \\
\frac{\partial v_{1}}{\partial x}+\frac{\partial v_{2}}{\partial y}=0
\end{array}\right.
$$

In this case, it is necessary to use the optimal model of the turbulent flow velocity obtained in this work:

$$
\left\{\begin{array}{c}
\frac{\partial v_{1}}{\partial t}+\alpha\left(\sigma \frac{\partial v_{1}}{\partial x}+\tau \frac{\partial v_{1}}{\partial y}\right)=-p_{1}+v \Delta v_{1}- \\
-\frac{1}{2 \alpha_{3}} \int_{0}^{h} \int_{0}^{l} R(t, \omega) v_{1}(t, \beta, \gamma) d \beta d \gamma- \\
-\frac{1}{2 \alpha_{3}} k_{1}(t, x, y)+q_{1} \\
\frac{\partial v_{2}}{\partial t}+\alpha\left(\sigma \frac{\partial v_{2}}{\partial x}+\tau \frac{\partial v_{2}}{\partial y}\right)=-p_{2}+v \Delta v_{2}- \\
-\frac{1}{2 \alpha_{3}} \int_{0}^{h} \int_{0}^{l} R(t, \omega) v_{1}(t, \beta, \gamma) d \beta d \gamma- \\
-\frac{1}{2 \alpha_{3}} k_{2}(t, x, y)+q_{2} \\
\frac{\partial v_{1}}{\partial x}+\frac{\partial v_{2}}{\partial y}=0
\end{array}\right.
$$

The system of linear equations (20) with the corresponding initial and boundary conditions (15) can describe the real process so that the fluid flow rate approaches as much as possible, perhaps, experimentally obtained for the modes $\varphi=\left(\varphi_{1}, \varphi_{2}\right), \quad \psi=\left(\psi_{1}, \psi_{2}\right)$. Equations $\left(19^{\prime}\right)$ are further simplified if a process without a gradient flow is considered. Note that to obtain technical data, it is convenient to solve the first of these equations by the method of separation of variables. конструирование

\section{Possible applications in problems of optimal design of reliable energy systems}

In system (20), the integrand function $R(t, x, y)$, i.e. the analytically exact positive solution of the nonlinear Riccati equation found above is the stabilizing integral core of the fluid velocity, which is very important in the process of heat transfer in general and the reliability of the model power system under consideration; $k(t, x)$ the solution of the linear equation (9) takes into account the influence of a constantly acting force $f_{1}(x, t)$, also from the experience of the accepted-desired function-velocity $\varphi(x, t)$. A constantly acting force can characterize the influence of geometric parameters on the flow rate, for example, it can take into account the effect of a noncircular cross section in bent or rough pipes. It should be noted that the optimal practical calculations of the operating mode of the heating device and pump should be carried out using the formulas of the synthesizing functions of the controls from (6-11).

Thus, the proposed mathematical model of the optimal fluid velocity differs significantly from the traditionally used mathematical model of the heat transfer process [14] and will be useful in practical calculations of the reliability of power systems. It (the system of equations (20)) will also be useful in specifying the values of the optimal heat transfer parameters as a whole, which is an important technical aspect of the reliability of power systems.

Note that if the end of the time interval of the heat transfer process is not fixed, then in the system of equations (20) it is necessary to set $\frac{\partial v_{1}}{\partial t}=0, \frac{\partial v_{2}}{\partial t}=0$ and this system of equations in this case is simplified.

\section{Conclusion}

The proposed methods of optimal control for studying the heat transfer process, the Riccati equation solving system and problems of optimal modeling, as well as the indicated methods of linearizing the system of NavierStokes equations and the stabilizing additional terms introduced in it, the obtained optimal functional dependence of the heating device and pump will be useful in research and analysis practically required tasks. The simplified mathematical models indicated in the work can be widely used in calculating and refining physical parameters (for example, the boundary layer of the fluid flow), which is an important point in technology and the optimal design of reliable energy systems in general.

In this regard, in theoretical results and apply the found optimal model of the heat transferring process (the system of Navier-Stokes equations with stabilizing additional terms) and the optimal functional dependence on the pump and heating device mode's fluid flow rate.

\section{References}

1. С.Г.Назаров, М.Р. Рахимов, Г.Х. Хекимов, Об оптимальном моделировании теплопередачи вязкой несжимаемой жидкости. В сборнике трудов 92-го заседания Международного научного семинара им. Ю.Н. Руденко «Методические вопросы исследования надежности больших энергетических систем», доклад №118, Иркутск - Казань, 21 - 26 сентябрь (2020)

2. О.А. Ладыженская, Математические вопросы 
динамики вязкой несжимаемой жидкости. М.: Наука, (1970) 288 с.

3. С.М. Белоносов, К.А. Черноус, Краевые задачи для уравнения Навье-Стокса. М.: Наука, (1985) $312 \mathrm{c}$.

4. Р. Темам, Уравнения Навье-Стокса, М.: изд. "Мир", (1981) 408 с.

5. S. Hijazi, G. Stabile, A. Mola, G. Rozza, DataDriven POD-Galerkin Reduced Order Model for Turbulent Flows, Int. arXiv:1907.09909v3 [math. NA] 5 Feb (2020)

6. А.Д. Клюквин, Анализ влияния зависимости теплофизических свойств воздуха от температуры на точность расчета параметров турбулентных течений при различных видах осреднения уравнений НавьеСтокса, Научное издание МГТУ им. Н.Э. Баумана, Наука образование, Эл. журнал, (2014) №8. C. 256-267, DOI: 10.7463/0814.0725648.

7. Н.М. Евстигнеев, Численный метод решения уравнений Навье-Стокса на неструктурированных сетках с применением Лагранжево-Эйлерового метода, Научнотехнические ведомости СПбГТУ 1' (2010)

8. Ж.-Л. Лионс, Управление сингулярными распределенными системами. М.: Мир (1987) $368 \mathrm{c}$.

9. М. О. Рахимов, применение методов спектрального разложения и динамического программирования $\kappa$ задачам оптимального управления системами $c$ распределенными параметрами. Докторская диссертация, МГУ им. М.В.Ломоносова, факультет ВМК, (1991)

10. В.А. Ильин, О безусловной базисности на замкнутом интервале систем собственных и присоединенных функиий дифференциального оператора второго порядка. Докл. АН СССР, (1983) T. 274, №1 c. 19-22.

11. А.И. Егоров, Оптимальное управление тепловыми и диффузионными процессами. М.: Наука, (1978) 464 с.

12. А.Г. Бутковский, Методы управления системами с распределенными параметрами. М.: Наука, 1975. $-568 \mathrm{c}$.

13. Сиразетдинов Т.К. Оптимизация систем с распределенными параметрами. М.Наука, (1977) $480 \mathrm{c}$.

14. М.Е. Дейч, А.Е. Зарянкин, Гидрогазодинамика. . М.: Энергоатомиздат, (1984) 384 с. 